\title{
Analgesic Efficacy of Paracervical Block for Manual Vacuum Aspiration of Incomplete Abortions: A Randomized Controlled Trial
}

\author{
Ekundayo 0. Ayegbusi ${ }^{1}$, Akintunde 0. Fehintola ${ }^{1}{ }^{*}$, Akinyosoye D. Ajiboye ${ }^{1}$, Ayodele Idowu ${ }^{2}$, \\ Tope 0. Okunola ${ }^{3}$, Michael S. Archibong1, Olajide E. Babalola1, Olusegun O. Badejoko', \\ Morebise 0. Loto ${ }^{1}$
}

\begin{abstract}
${ }^{1}$ Department of Obstetrics, Gynaecology, and Perinatology, Faculty of Clinical Sciences, College of Health Sciences, Obafemi Awolowo University, Ile Ife, Osun State. Nigeria

${ }^{2}$ Department of Obstetrics and Gynaecology, State Specialist Hospital, Ikare Akoko, Ondo State, Nigeria

${ }^{3}$ Department of Obstetrics and Gynaecology, Ekiti State University Teaching Hospital, Ado-Ekiti, Ekiti State, Nigeria

Email: *fehintolaakintunde@gmail.com
\end{abstract}

How to cite this paper: Ayegbusi, E.O., Fehintola, A.O., Ajiboye, A.D., Idowu, A., Okunola, T.O., Archibong, M.S., Babalola, O.E., Badejoko, O.O. and Loto, m.o. (2021) Analgesic Efficacy of Paracervical Block for Manual Vacuum Aspiration of Incomplete Abortions: A Randomized Controlled Trial. Open Journal of Obstetrics and Gynecology, 11, 955-972.

https://doi.org/10.4236/ojog.2021.118091

Received: July 12, 2021

Accepted: August 6, 2021

Published: August 9, 2021

Copyright (c) 2021 by author(s) and Scientific Research Publishing Inc. This work is licensed under the Creative Commons Attribution International License (CC BY 4.0).

http://creativecommons.org/licenses/by/4.0/ (c) (i) Open Access

\begin{abstract}
Introduction: Pain control during Manual Vacuum Aspiration is one of the most important aspects of postabortion care. This study assessed the analgesic efficacy, requirement for additional analgesia, and overall satisfaction using Paracervical blocks of $1 \%$ lignocaine compare with normal saline as placebo among women undergoing manual vacuum aspiration for incomplete abortion in OAUTHC, Ile-Ife. Methods: This was a double blind randomized controlled trial that occurred between January 2019 and February 2020. We randomized one hundred and twenty eligible women equally into 2 groups. Group A received paracervical block using 1\% lignocaine while those in group B received paracervical block using normal saline as placebo. We obtained ethical clearance from the Ethics and Research Committee of the hospital. Preoperatively, we obtained relevant data and evaluated the degree of anxiety and pain on a visual analog scale (VAS). Intraoperative pain was evaluated from 2 viewpoints: that of the external observer on a 0 - 4 scale and that of the patient scale of 0 - 10 in the immediate postoperative period, followed by overall satisfaction at the point of discharge. We analyzed the data using SPSS version 20. Paired T test, independent $\mathrm{T}$ test Chi square, and Fishers' exact tests were applied for continuous and categorical variables as appropriate. $\mathrm{P}$ value $<$ 0.05 was considered as statistically significant. Results: The Intra-operative and Postoperative VAS was significantly higher in the placebo group compared to the analgesia group $(\mathrm{t}=-3.39, \mathrm{CI}-4.11--2.69 . \mathrm{P}<0.05$ intra-operative, $\mathrm{t}=$ 7.18, CI $2.62-4.61$. $\mathrm{P}<0.05$ post-operative). The need for additional analgesia and mean VAS of those in the placebo group was significantly higher than
\end{abstract}


that of the study group with higher overall satisfaction rate in the study group $(t=7.18$. CI $2.62-6.71 . \mathrm{P}<0.0001)$. Conclusions: Paracervical block with $1 \%$ lignocaine is more effective in reducing pain during manual vacuum aspiration compared to placebo. It has added advantage of a higher overall satisfaction rate and reduced need for additional analgesia.

\section{Keywords}

Postabortion Care, Pain, Placebo, Paracervical Block

\section{Introduction}

Abortion (or miscarriage) is one of the most common causes of gynaecological consultation and hospital admission [1] and irrespective of the cause, instituting a timely care could go a long way in securing the woman's reproductive health.

Abortion could be spontaneous (i.e. Miscarriage) or Induced. Induced abortion is the purposeful termination of pregnancy by expulsion of an embryo from the uterus prior to viability [2]. World Health Organization WHO defines miscarriage as the spontaneous expulsion from its mother of a fetus or an embryo weighing 500 grams or less [3] [4] [5]. This corresponds to a gestational age of about 20 to 22 weeks. However, studies in Nigeria and most Africa countries recognize 28 weeks as age of viability and define abortion as the termination of pregnancy before 28 weeks of gestation [6]. These definitions seek to indicate the time the fetus is able to live a separate existence from the mother, that is, when the fetus is viable. With the advancement in technology, specifically neonatal care, fetuses delivered at $22-24$ weeks are surviving. This is why WHO put age of viability at $20-22$ weeks in its definition.

About one-third of all pregnancies worldwide would end in miscarriage/spontaneous abortion, stillbirth, or induced abortion and at least 15\% $20 \%$ of all clinically recognized pregnancies end in spontaneous abortion [1] [2] [3] [6] [7] [8] [9]. It constitutes about $25 \%$ to $30 \%$ of all gynaecological admissions in most developing countries [6].

Incomplete abortion, (when the entire product of conception is not expelled, whether spontaneous or induced), which is the focus of this study, usually presents with the clinical features of, lower abdominal pain and vaginal bleeding following a period of amenorrhea, with or without the symptoms of pregnancy. The cervix is dilated and the products of conception may be protruding through the cervical os [2] [4] [10]. Pregnancy test and ultrasonography are helpful in making diagnosis, especially in the very early gestational age as they distinguish it from other causes of abnormal uterine bleeding [5].

Surgical evacuation particularly, manual vacuum aspiration technique, is the standard method of uterine evacuation and has been shown to be simpler, cheaper, safer, much more effective and easier to use than the traditional dilatation and curettage technique in preventing post abortal complications [2] [7] [8] [11]. 
Pain control during gynecologic procedures including first trimester surgical abortion, especially mva for incomplete abortion is particularly a significant issue for women [5]. An effective pain control must be able to block or prevent transmission of sensation from the parasympathetic fibers of $s 2$ to $s 4$ which innervate the cervix and the lower uterine segment and sympathetic fibers from t10 to 11 which innervate the uterine fundus [6] [7] [8] [9]. Pain perception is a complex phenomenon with physical and psychosocial interactions which vary considerably among women. Therefore, regardless of whether patients undergo dilation and curettage with sharp curette or manual vacuum aspiration, sufficient management of pain during the process of evacuating the uterus, is one of the keys to successful treatment of incomplete abortion [10] [11]. Patients may experience two types of pain with manual intrauterine aspiration. Severe visceral pain that occurs during dilation of the cervix, as well as with the stimulation of the internal cervical ostium, which is transmitted by the dense network of nerves that surround the cervix (parasympathetic s2 to s4), and the diffuse, colic pain, sometimes inform of cramps caused by moving the uterus, curettage of the uterine wall, and muscle spasm secondary to emptying the uterine cavity (sympathetic t10 to 11 ).

They are transmitted from the fundus through these uterine nerves that follow the uterosacral and utero-ovarian ligaments. The hypogastric plexus innervates the body and fundus of the uterus, while the uterovaginal plexus innervates the cervix and upper portion of the vagina [12].

The perception of pain varies from individual to individual and also varies at different times and parts for the same individual [13]. Thus, pain perception is subjective and this led to various instruments to objectively measure pain perception. These include the Visual Analogue Scale (VAS) [13], Numerical Rating Scale (NRS), Simple Descriptive Scale (SDS), Verbal Rating Scale (VRS), use of colours and faces for children.

The most commonly used scale is the visual analog scale. A change in the visual analog scale score represents a relative change in the magnitude of pain sensation. Use of the vas in comparative analgesic trials can now meaningfully quantify differences in potency and efficacy [13]. For the purpose of this study visual analog scale (vas) was used to assess the pain score because it is believed to be more objective, easy to understand and administered.

While a variety of options are available for analgesia, evidence elucidating the efficacy of these options is limited. Currently, selection of analgesia for first trimester surgical abortion is primarily guided by literature on other gynecological procedures involving dilation of the cervix in conscious patients [5] while these studies provide useful insight, the issue of pain control during abortion is complicated not only by the psychosocial aspects of pain (especially if the pregnancy is wanted), but also by the context of a procedure so deeply stigmatized as abortion. Unfortunately, guidelines for appropriate pain management during treatment of incomplete abortions are few, not usually very clear and not even available in most of our centres.

Paracervical blocks are used widely in gynecologic procedures including first 
trimester surgical abortion. Though, general anaesthesia provides adequate operating conditions during uterine intervention however, there are some situations where general anaesthesia is hazardous, for example when patients are frail, unwell, or when no anaesthesiologist is available. The choice of anaesthesia and analgesia is dependent on effectiveness, cost, safety, and side effects. The term para cervical block refers to the injection of local anesthesia into the cervix. Usually 10 $20 \mathrm{ml}$ of $0.5 \%-1.0 \%$ plain lidocaine solution (always less than $200 \mathrm{mg} /$ person, as toxicity occurs at that level). Lidocaine is the most common local anesthetic agent with a characteristic of easy availability, low cost, stability and low risk of allergic/adverse reaction. In comparison, general anesthesia requires the increased complexity of care and the associated costs. It requires some degree of preoperative patient preparation. It causes the greatest number of side effects and complications even stroke. It requires a special team of a doctor and technicians. Spinal and epidural anesthesia also needs anesthetist. On the other hand local anesthesia can be managed by clinician him/herself. Side effects to lignocaine are not common partly due to reduced concentration that is commonly used, the following side effects have been reported however, hypersensitivity and allergic reaction, light-headedness, dizziness, blurred vision, restlessness, tremor, and rarely, especially in overdose occasional convulsion, unconsciousness with respiratory distress. Cardiovascular toxicity includes hypotension, and very rarely heart block. These are all avoidable, by using appropriate concentration (1\%) and preventing an inadvertent injection of drug into the blood vessels, this is by doing test aspiration before injection [14] [15] [16] [17]. There is little information about how useful local anaesthesia is when manual vacuum aspiration is used for treating incomplete abortion and available studies have evaluated the efficacy of local anesthesia in patients with abortions with a closed cervix, and as such, the evidence cannot be directly extrapolated to the treatment of incomplete abortion, in which the cervix is usually open [17] [18] when the cervix is closed, it is necessary to dilate the cervix through mechanical procedures; this is the most painful part of the procedure [10] [19] [20] which is not necessary in incomplete abortion because the cervix is open. Therefore, the role of paracervical block in this group of abortion is less clear couple with the paucity of such studies in our environment. Hence, the study of analgesic efficacy and tolerability of paracervical block in this group.

\section{Methods}

\subsection{Study Location}

This study was conducted at the department of obstetrics and gynaecology, obafemi awolowo university teaching hospital complex, ile-ife between January 2019 and February 2020. The hospital comprises mainly two arms offering tertiary healthcare; the ife hospital unit in ile-ife, and the Wesley guild hospital unit in Ilesha. Both of them are located in Osun state, south-west Nigeria.

\subsection{Study Design}

The study was a double blind randomized controlled trial. 


\subsection{Inclusion/Exclusion Criteria}

We included omen between the age of 18 to 45 years with the diagnosis of incomplete abortion, (expulsion of some but not all the products of conception) with an evidence of open cervix, (spontaneous or induced) at a gestational age of 12 weeks or less in the study. Other inclusion criteria were patients who were heamodynamically stable. (PCV $\geq 30 \%$ ) and patients who were capable of giving informed consent. We excluded patients with septic abortion, psychiatric or neurological disease, hypovolemic or septic shock, signs of peritonitis, allergies to lidocaine or previous history of adverse side effects to lidocaine, and patients who refused consent

\subsection{Sample Size Determination}

The minimum sample size required for the determination of the mean score for pain perception of the two groups in this study was calculated using the sample size formula for the comparison of mean by Jekel et al. [21] as follows:

$$
N=2 \times\left(\frac{Z \alpha+Z \beta}{d}\right)^{2} \times S^{2}
$$

$N /$ per group $=$ minimum sample size per group .

$Z \alpha=$ standard normal deviate of $\alpha$ at 95\% confidence level, (i.e. probability of making a type 1 error $)=1.96$.

$Z \beta=$ standard normal deviate of $\beta$ at $80 \%$ confidence level (i.e. probability of making a type 2 error) $=0.84$.

$d=$ minimum difference in mean pain scores between the two groups that the investigator is willing to accept $=2$ (scores on scale visual analogue).

$s=$ standard deviation of the pain scores during manual vacuum aspiration across paracervical block and placebo groups that are the pooled estimate of the standard deviation in the two groups $=3.81$ as extrapolated from findings [22] in the study by Renner et al. 2012

$$
N=2 \times\left(\frac{1.96+0.84}{2}\right)^{2} \times 3.81^{2}
$$

$N=2 \times(1.4)^{2} \times 3.81^{2}$.

$N=2 \times(1.4)^{2} \times 14.5$.

$N=56.9=60$.

The sample size was therefore rounded up to 60 patients for each group.

Hence, a total of 120 women were studied.

\subsection{Training of Research Assistants}

Prior to the commencement of this study, eight registrars in the department (four in each hospital unit) that have been properly trained during the departmental routine IPAS training sessions on the proficiency of manual vacuum aspirations (MVA) and administration of analgesics/anaesthesia, including paracervical blocks in MVA were recruited. Training sessions were also organized by the researcher for these registrars and two other senior registrars that were in- 
volved in this study, with a protocol detailing the aims and methodology of the study fully discussed and any ambiguity clarified.

The two senior registrars, (one for each hospital) were trained on the administration of preoperative pain, anxiety, intraoperative pain and postoperative overall satisfaction (at the point of discharge) scores on the visual analogue scale.

\subsection{Recruitment of Patients and Baseline Data Collection}

Women who presented at the gynaecology emergency of the two hospital units between January 2019 and February 2020 and are diagnosed as having an incomplete abortion and who fulfilled all the selection criteria above were invited to participate in the study. Before treatment, each potential participant received detail information about the study and was asked to participate voluntarily if she so desired. All participants signed the study's informed consent form. Sociodemographic data as stated above, such as age, gestational age, and educational level, with family and social information were collected.

Gestational age was calculated based on the date of the first day of the last menstrual period, in cases in which there was certainty regarding this. When there was doubt, this date/diagnosis was determined by an earlier ultrasound. Socioeconomic status was ascertained using Olusanya et al. social classification [23]. Participants were also asked about the number of previous gestations, the timing of the onset of abortion, the presence of pain, the prior use of analgesics or abortifacients, and the desire to be pregnant. For the physical examination, the presence of abdominal pain, uterine size, and the state of the cervix; (open or closed) were evaluated. All data were registered in the patient's clinical chart and in a case report form specifically designed for such purposes.

\subsection{Allocation of Patients into Groups}

All the patients received counseling before, during, and after the procedure, they were informed about the role of each individual inside the operating room, explaining clearly about what will be happening during the entire process, and identifying and responding to the women's concerns. Consenting participants were treated in the casualty theatre, where the randomization group assignment was opened and administered prior to the procedure.

Participants were allocated into 2 groups of Groups A and B by block randomization generated using a computational algorithm by a trained Statistician. At presentation in the gynaecology emergency unit, Participants assigned to group A received paracervical block using $1 \%$ lignocaine whereas those assigned to group B received paracervical block of normal saline as placebo before the manual vacuum aspiration procedure.

The randomization distributions, which were prepared at the accident and emergency pharmacy, were kept in sealed, sequential opaque envelopes kept in the fridge and opened only when a study participant had consented to the study and in the operating theatre for treatment, using consecutive sampling technique.

The investigator, the patients, external observer and outcome determinants 
were blinded to the intervention each patient received.

\subsection{Procedure of Paracervical Block and Manual Vacuum Aspiration}

During the preoperative period, anxiety and preoperative pain score scale were administered, in which a trained observer asked the woman to evaluate the degree of anxiety on a visual analog scale, the scale ranged from 0 , meaning no anxiety, to 10, meaning maximum anxiety, as well as the level of preoperative pain from 0 no pain to 10 extreme pain [23] and the patients were informed to take a mental note of the pain perceived during the procedure.

Women were randomized to receive either paracervical block of $20 \mathrm{~mL} 1 \%$ lignocaine or $20 \mathrm{ml}$ of normal saline, the paracervical blocks chosen for this study was based on techniques supported by the literature [17] [18] [19] [24] [25] [26] and the manual vacuum aspiration was performed according to standard clinical protocol; as follows: The patients were asked to empty their bladder, placed in lithotomy position and appropriate antibiotics given.

The vagina, vulva, pubis, perineum and inner aspects of the thighs were cleaned with chlorhexidine solution and sterile drapes were applied. Bimanual pelvic examinations were done and note the findings.

The randomized, assigned specific sealed, opaque envelope which contains either a Syringe loaded with $20 \mathrm{~mL}$ of $1 \%$ lignocaine or $20 \mathrm{ml}$ of normal saline as the case may be, which had been kept in the fridge at $4^{\circ} \mathrm{C}$ was opened and attached to a 21-gauge spinal needle.

$2 \mathrm{ml}$ was injected at the tenaculum site; that is 12 o'clock superficially into the cervix. An Auverd weighted speculum or Sims speculum was introduced to retract the posterior vaginal wall thereby exposing the cervix, the tenaculum was placed immediately at 12 o'clock, while the remaining $18 \mathrm{~mL}$ was injected slowly over $60 \mathrm{sec}$ into the cervicovaginal junction in four equal aliquots of $4.5 \mathrm{mls}$ at 2 , 4,8 , and 10 o'clock; the injection was continuous from superficial to deep $3 \mathrm{~cm}$ to superficial injecting with insertion and withdrawal to carefully avoid accidental injection of the medication into the blood vessels. Five minutes after administration of the study solution, during which patients would have been told again to take a mental note of the pain perceived during the procedure, the gynecologist using the manual vacuum aspiration technique, commenced evacuation of the uterus, initially, by using an appropriately sized suction cannula, for uterine sound to determine its depth. This was then followed by connecting it to the MVA syringe after a vacuum had been created in it. The vacuum was released and products of conception evacuated by a gentle rotatory, in and out motion of the cannula until gritty sensation was felt and foamy of blood aspirated from the uterine cavity. An appropriate oxytocic agent was administered.

Intraoperative pain was evaluated from 2 viewpoints: that of the external observer on a $0-4$ visual analogue scale during the procedure and that of the patient on the visual analogue scale of $0-10$, immediately after the postoperative period.

During this procedure, the trained external observer, who was also blinded to 
the patient's group assignment, evaluated and scored the patient's intraoperative pain by using the visual analogue scale as follows:

0 : Patient did not show any sign of pain.

1: Patient showed pain through facial expressions.

2: Patient verbally and spontaneously expressed pain.

3: Patient indicated pain with verbal and facial expressions but allowed the procedure to continue.

4: Patient did not let the procedure continue without analgesia or anesthetic medication for the pain and demonstrated this by verbal or bodily expression.

Immediately after the procedure, patient's personal assessment of intraoperative pain was also scored, in which the patient was asked to describe the pain that she had felt during the manual vacuum aspiration by using the same visual analog scale used in evaluating preoperative pain.

The products were sent for histopathological examination. Both procedures of paracervical block and manual vacuum aspiration were done under aseptic techniques, the time the procedure lasted and any complications were noted. In the postoperative period, patients' vital signs were monitored every 15 minutes until stable and normal, if no undue vaginal bleeding or pain, postoperative overall satisfaction (at the point of discharge) was administered on the visual analogue scale and discharge home on oral medications.

Patients received follow-up care according to standard care procedures. Oral Ampiclox $500 \mathrm{mg} 6$ hourly with Oral Metronidazole $400 \mathrm{mg} 8$ hourly for 5 days and Oral Paracetamol $1 \mathrm{~g} 8$ hourly for 3 days were given.

\subsection{Study Outcomes}

\section{Primary study outcomes}

1) Mean intraoperative pain score as evaluated by the patient and external observer in the two groups. The pain expressed by the patient was measured, using pain visual analogue scale chat.

2) Evaluate patients' postoperative overall satisfaction (at the point of discharge) scores on the visual analogue scale.

\section{Secondary study outcomes}

1) The need for additional analgesics, which was administered when VAS by external observer is equal to or greater than 2 (I.M Diclofenac $75 \mathrm{mg}$ stat \& Midazolam $5 \mathrm{mg}$ stat).

2) Assess side effects; such as metallic taste, hypersensitivity and allergic reaction, light-headedness, dizziness, blurred vision, restlessness, tremor, and convulsion.

All the Patients were evaluated in the groups to which they were assigned according to the analysis of the intention to treat and the randomization code was broken at the end of the study to identify the intervention that each patient received.

\subsubsection{Statistical Analysis}

The data obtained from this study were analyzed using SPSS version 16 . The ef- 
fectiveness, that is, the mean visual analog scale (VAS) pain scores in patients undergoing manual vacuum aspiration for incomplete abortion using Paracervical block with $1 \%$ lignocaine and paracervical block with normal saline were assessed, and the side effects of lignocaine during the procedure. Other interactions were considered, including the requirement for additional analgesia. Paired $\mathrm{T}$ test and independent $\mathrm{T}$ test were applied for continuous variables as appropriate. Chi square test and fisher exact test were applied for categorical variables as appropriate, a p value $<0.05$ was considered as statistically significant.

\subsubsection{Ethical Consideration}

Ethical clearance was obtained for this study from the Ethics and Research Committee of Obafemi Awolowo University Teaching Hospitals Complex, Ile-Ife. All participants were duly informed about the study, and reserve the right to voluntarily withdraw for whatever reasons without penalty.

\subsubsection{Assessment of Safety}

Adverse effects were noted and reviewed. The investigator was responsible for the cost of treating any adverse events.

\section{Results}

During the study period between April 2016 and October 2016 there were a total of 486 gynaecological admissions via the gynaecological emergency of the two hospital units (Ife hospital unit and Wesley guild hospital unit); out of these, 258 were cases of abortion giving an overall incidence of 53.1\%. 127 (49.2\%) were spontaneous abortions while 131 (50.8\%) were induced abortions. A total of 216 (83.7\%) of these were incomplete abortions at presentation, out of which 120 patients were recruited for the study.

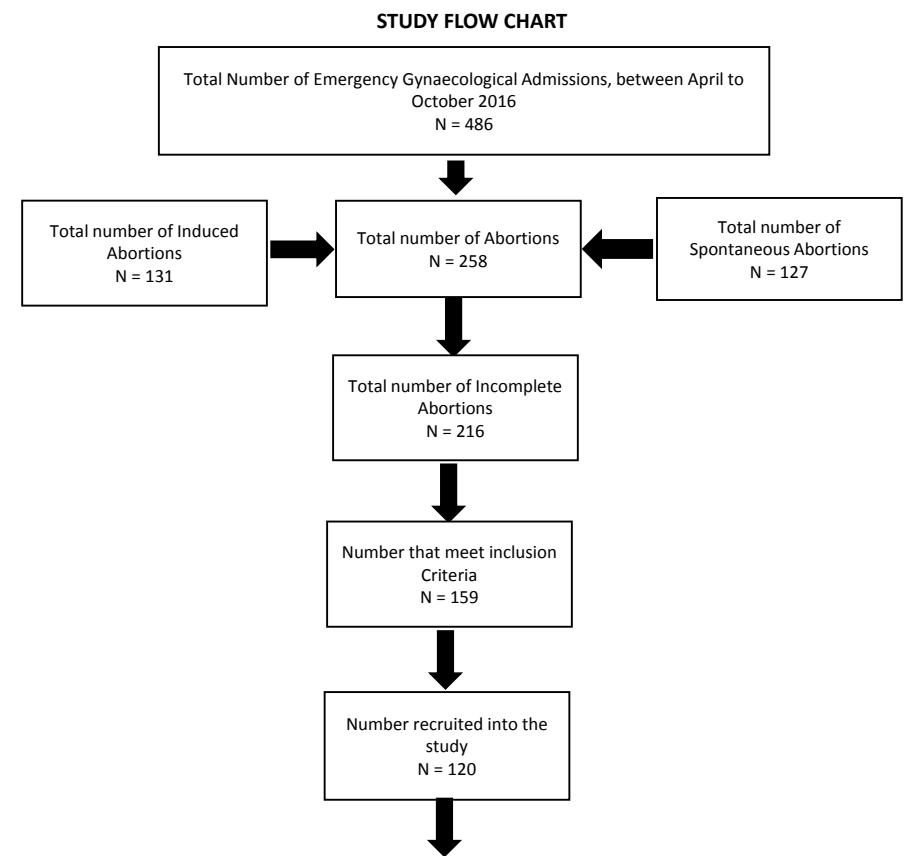




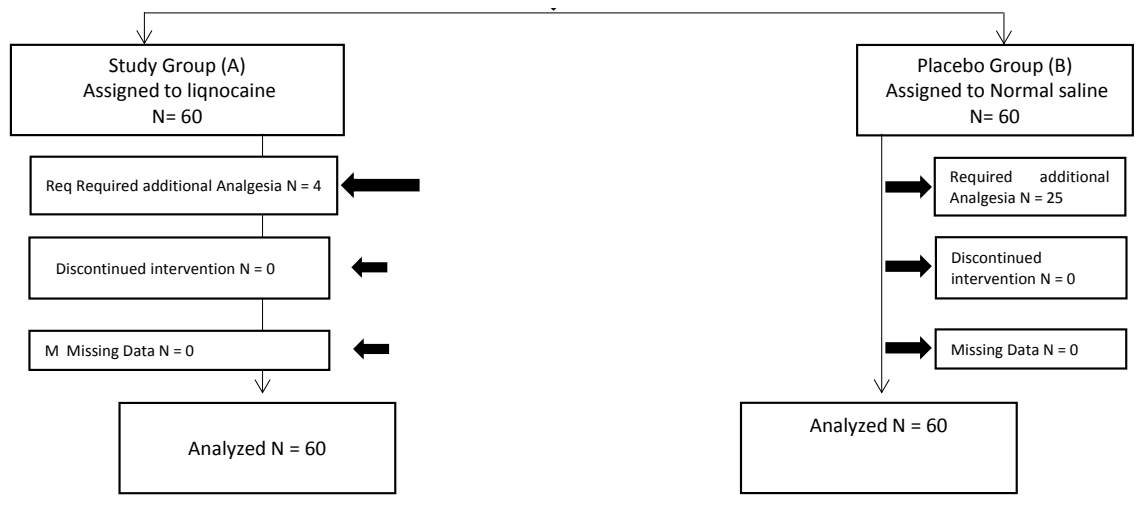

The baseline characteristics between the two groups revealed no statistically significant difference across board; the mean age between the study group and the placebo group was (29.4 vs. 32.9 years, $\mathrm{P}>0.05)$, the parity between the two groups revealed ( 4.8 vs. $4.5, \mathrm{P}>0.05$ ), while estimated gestational age showed (7.1 vs. 6.6 weeks, $\mathrm{P}>0.05$ ), and the social class was ( 3.8 vs. $3.8, \mathrm{P}>0.05$ ) (Table $1)$.

There were 90 married women in both groups, (38 out of these, were in the study group while 52 in the placebo group) and 30 were found to be single (with 22 single women in the study group and 8 in the placebo group), 69 out of all the pregnancies were wanted (study group 30 \& placebo group 39) while 51 were unwanted (study group 30 \& placebo group 21), 41 pregnancies were induced abortions (study group $29 \&$ placebo group 12) while as many as 79 pregnancies were spontaneous abortions (study group 31 \& placebo group 48), expectedly only 16 pregnancies were already booked as at the time of abortion (study group 9 \& placebo group 7) while the majority, 104 pregnancies were unbooked (study group 51 \& placebo group 53) and among all the 120 women with incomplete abortions studied only 37 had previous experience of MVA (study group 25 \& placebo group 12) while 83 had no previous history of such experience (study group 35 \& placebo group 48). The patients were similar in their marital status $(P=0.063)$, types of abortion $(P=0.253)$, booking status $(P=0.395)$, previous history of MVA $(\mathrm{P}=0.119)$ and also whether the pregnancy was wanted or not, did not have any significant relationship with analgesic efficacy in the two groups in OAUTHC, Ile-Ife (Table 2).

The preoperative visual analogue scale for anxiety and pain scores between the two groups revealed no statistically significant difference with $(t=0.79, P>0.05)$ and $(t=3.07, P>0.05)$ respectively. However, the intraoperative period revealed a statistically significant difference in the pain visual analogue scores observed by the external observer in the two groups $(\mathrm{t}=-3.39, \mathrm{P}<0.05)$ and the pain visual analogue score expressed by the patient $(t=-9.52, \mathrm{P}<0.05)$. It was also noted that the mean VAS for pain expressed under the placebo group was significantly higher than that of the study group). This study further showed a statistically significant difference in the postoperative period satisfaction visual analogue score $(\mathrm{t}=7.18, \mathrm{P}<0.05)$ (Table 3$)$. 
Table 1. Comparison of baseline characteristics between groups.

\begin{tabular}{|c|c|c|c|c|c|c|c|}
\hline & \multirow{2}{*}{$\begin{array}{c}\text { Study group } \\
\text { Mean } \pm \text { SD }\end{array}$} & \multirow{2}{*}{$\begin{array}{c}\text { Placebo group } \\
\text { Mean } \pm \text { SD }\end{array}$} & \multirow{2}{*}{$\begin{array}{c}\text { Mean } \\
\text { difference }\end{array}$} & \multirow{2}{*}{ T value } & \multirow{2}{*}{ P value } & \multicolumn{2}{|c|}{$95 \%$ C. I } \\
\hline & & & & & & Lower & Upper \\
\hline Age & $29.4 \pm 7.2$ & $32.9 \pm 6.1$ & -3.53 & -2.89 & 0.115 & -5.95 & -1.11 \\
\hline Parity & $4.8 \pm 3.5$ & $4.5 \pm 2.9$ & 0.31 & 0.53 & 0.594 & -0.85 & 1.48 \\
\hline EGA & $7.1 \pm 1.9$ & $6.6 \pm 1.9$ & 0.48 & 1.41 & 0.163 & -0.98 & 1.16 \\
\hline Social class & $3.8 \pm 0.7$ & $3.8 \pm 0.6$ & 0.01 & 0.13 & 0.898 & -0.24 & 0.27 \\
\hline
\end{tabular}

EGA: Estimated Gestational Age.

Table 2. Comparison of categorical baseline characteristics between both groups.

\begin{tabular}{|c|c|c|c|c|c|c|}
\hline Parameters & Classification & $\begin{array}{l}\text { Study group } \\
\mathrm{N}(\%)\end{array}$ & $\begin{array}{l}\text { Placebo } \\
\text { N (\%) }\end{array}$ & $\begin{array}{l}\text { Total } \\
\text { N (\%) }\end{array}$ & $\begin{array}{c}\mathrm{X}^{2} \\
\text { Fisher exact test }\end{array}$ & $P$ value \\
\hline \multirow{3}{*}{ Marital status } & Married & $38(31.7)$ & $52(43.3)$ & $90(75.0)$ & \multirow{3}{*}{0.006} & \multirow{3}{*}{0.063} \\
\hline & Single & $22(18.3)$ & $8(6.7)$ & $30(25.0)$ & & \\
\hline & Total & $60(50)$ & $60(50)$ & $120(100)$ & & \\
\hline \multirow{3}{*}{ Types } & Spontaneous & $29(24.2)$ & $12(10.0)$ & $41(34.2)$ & \multirow{3}{*}{0.002} & \multirow{3}{*}{0.253} \\
\hline & Induced & $31(25.8)$ & $48(40.0)$ & $79(65.8)$ & & \\
\hline & Total & $60(50)$ & $60(50)$ & $120(100)$ & & \\
\hline \multirow{3}{*}{$\begin{array}{l}\text { Booking } \\
\text { status }\end{array}$} & Booked & $9(7.5)$ & $7(5.8)$ & $16(13.3)$ & \multirow{3}{*}{0.789} & \multirow{3}{*}{0.395} \\
\hline & Unbooked & $51(42.5)$ & $53(44.2)$ & $104(86.7)$ & & \\
\hline & Total & $60(50)$ & $60(50)$ & $120(100)$ & & \\
\hline \multirow{3}{*}{$\begin{array}{l}\text { Previous } \\
\text { history of } \\
\text { MVA }\end{array}$} & Yes & $25(20.8)$ & $12(10.0)$ & $37(30.8)$ & \multirow{3}{*}{0.017} & \multirow{3}{*}{0.119} \\
\hline & No & $35(29.2)$ & $48(40.0)$ & $83(69.2)$ & & \\
\hline & Total & $60(50)$ & $60(50)$ & $120(100)$ & & \\
\hline \multirow{3}{*}{ Pregnancy } & Wanted & $30(25)$ & $39(32.5)$ & $69(57.5)$ & \multirow{3}{*}{0.139} & \multirow{3}{*}{0.070} \\
\hline & Unwanted & $30(25)$ & $21(17.5)$ & $51(42.5)$ & & \\
\hline & Total & $60(50)$ & $60(50)$ & $120(100)$ & & \\
\hline
\end{tabular}

MVA: Manual Vacuum Aspiration.

Table 3. Comparison of visual analogue scale of pain and anxiety scores between the two groups.

\begin{tabular}{|c|c|c|c|c|c|c|c|}
\hline & \multirow[b]{2}{*}{$\begin{array}{c}\text { Study group } \\
\text { Mean } \pm \text { SD }\end{array}$} & \multirow[b]{2}{*}{$\begin{array}{c}\text { Placebo group } \\
\text { Mean } \pm \text { SD }\end{array}$} & \multirow[b]{2}{*}{ Mean difference } & \multirow[b]{2}{*}{ T value } & \multirow[b]{2}{*}{$P$ value } & \multicolumn{2}{|c|}{$\begin{array}{l}95 \% \text { Conf. interval } \\
\text { of the difference }\end{array}$} \\
\hline & & & & & & Lower & upper \\
\hline Preopeartive period: Anxiety VAS & $9.6 \pm 1.7$ & $9.3 \pm 2.5$ & 0.32 & 0.79 & 0.428 & -0.47 & 1.10 \\
\hline Preoperative period: Pain VAS & $7.1 \pm 1.9$ & $6.0 \pm 1.8$ & 1.03 & 3.07 & 0.203 & 0.37 & 1.69 \\
\hline $\begin{array}{l}\text { Intraoperative period: Pain VAS by } \\
\text { ext observer }\end{array}$ & $1.1 \pm 0.5$ & $1.9 \pm 0.9$ & -0.48 & -3.39 & 0.001 & -0.77 & -0.20 \\
\hline Intraoperative period: Pain by patients & $3.2 \pm 2.1$ & $6.6 \pm 1.8$ & -3.40 & -9.52 & 0.000 & -4.11 & -2.69 \\
\hline $\begin{array}{l}\text { Postoperative period: Satisfaction } \\
\text { visual Analogue }\end{array}$ & $8.8 \pm 1.9$ & $5.2 \pm 3.4$ & 3.62 & 7.18 & 0.000 & 2.62 & 4.61 \\
\hline
\end{tabular}

VAS: Visual Analogue Score. 
The comparison of secondary outcomes by the two groups on the need for additional analgesia was statistically significant $(P$ value $<0.05)$ in which, a total of $86.2 \%$ (25) of the 29 women who required additional analgesia were from the placebo group; and only $13.8 \%$ (4) of them were from the study group (Table 4). A further comparison of the mean visual analogue score of patients that required additional analgesia showed a statistically significant difference between the two groups with a $\mathrm{P}$ value $<0.05$. It was noted that the mean VAS of those that required additional analgesia in placebo group was significantly higher (6.72) compare to that of the study group (2.75), there was however, no statistically significant difference in the mean VAS among the women that did not require additional analgesia in the two groups (Table 5). None of the patients in the two groups experienced any side effects, all the MVA procedures were completed, there was no need to suspend treatment or procedure throughout the period of the study, except occasional delays among the patients that require additional analgesia, there was no need to repeat the procedure and no complications were recorded.

\section{Discussion}

Abortion is one of the most common causes of gynaecological consultation and hospital admission [1] whether spontaneous or induced, instituting a timely care could go a long way in securing the woman's reproductive health and pain control, which is one of the most relevant aspects in managing incomplete abortion was the focus of this study.

In this study, the incidence of abortion is $53.1 \%$ which is higher than what was previously reported in this institution [27] [28]. This is probably because the previous studies were retrospective with possibility of loss of data as a result of poor record keeping and were also carried out only in Ife hospital unit (an arm of the

Table 4. Comparison of secondary of outcomes by the two groups.

\begin{tabular}{ccccccc}
\hline & & $\begin{array}{c}\text { Study group } \\
\text { N (\%) }\end{array}$ & $\begin{array}{c}\text { Placebo } \\
\text { N (\%) }\end{array}$ & Total & $\begin{array}{c}\text { Fisher Exact } \\
\text { test }\end{array}$ & P Value \\
\hline \multirow{2}{*}{$\begin{array}{c}\text { Needs for } \\
\text { additional analgesia }\end{array}$} & Yes & $56(46.7 \%)$ & $35(29.2 \%)$ & $91(75.8 \%)$ & & \\
& Total & $60(50.0 \%)$ & $25(20.8 \%)$ & $29(24.2 \%)$ & 0.000 & 0.000 \\
Side Effects & & Nil & Nil & Nil & & \\
\hline
\end{tabular}

Table 5. Comparison of the mean VAS of the requirement for additional analgesia in the two groups.

\begin{tabular}{ccccc}
\hline & $\begin{array}{c}\text { Study Group } \\
\text { NO (Mean VAS) }\end{array}$ & $\begin{array}{c}\text { Placebo Group } \\
\text { NO (Mean VAS) }\end{array}$ & $\begin{array}{c}\text { Chi Square } \\
\mathrm{X}^{2}\end{array}$ & P value \\
\hline Required & $4(2.75)$ & $25(6.72)$ & 10.23 & 0.007 \\
Not Required & $56(2.19)$ & $35(4.09)$ & 2.77 & 0.231 \\
\hline
\end{tabular}

VAS: Visual Analogue Score. 
hospital) while the present study is a prospective study which was carried out in both arms of the hospital (Ife Hospital Unit, Ile-Ife and Wesley Guild Hospital, Ilesha). It is however similar to $53.2 \%$ and $53.7 \%$ reported in Maiduguri and Uyo respectively [29] [30].

There was no significant relationship in the marital status and pain expressed using paracervical block during MVA of incomplete abortions between the 2 groups and this is also the same with parity, mean estimated gestational age, social class, and types of abortion. Booking status, previous MVA, and whether the pregnancy is wanted or not, were also not significantly different.

These baseline characteristics' similarities reveal that the randomization was largely successful and the similarities exhibited are also a demonstration to the fact that majority of the patients live in the same environment, so their baseline characteristics are likely to be closely related vis-à-vis other wellbeing indicators and psychosocial factors.

The preoperative anxiety score was high and similar in both groups, obviously all the patients were anxious; this further corroborates successful randomization and reveals an association between the preoperative anxiety and the pain experienced before the manual vacuum aspiration of an incomplete abortion.

Previous studies by Wiebe et al. and Stubblefield found out that women often feel nervous about undergoing uterine evacuation, and their anxiety may aggravate their perception of pain. Conversely, women who feel less anxious are less likely to perceive pain [23] [31] [32] detailed description of the study procedures however with step by step explanation of each stage to the women, could prepare and reduced the patient's anxiety before the procedure.

The comparison of the level of intraoperative pain experienced during the procedure between the 2 groups by both the external observer and the patient, revealed significant differences showing that the placebo group experienced more pain and this is similar to various studies already conducted; in the study done by Egziabher et al. [21], he assessed pain relief using paracervical block in patients undergoing manual vacuum aspiration of uterus, he reported that the untreated group experienced more pain than the treated group especially lower abdominal pain and backache [33]. Glanz et al. noted chloroprocaine was superior to saline in a 4 arm randomized trial involving 82 women undergoing first trimester abortion, the women reported significantly less pain during dilation and aspiration as well as after the procedure. In his study, Renner et al. observed that women who received paracervical block reported significantly less pain with both dilation (mean 42 compared with $79 \mathrm{~mm}, \mathrm{P}<0.001$ ) and aspiration (mean 63 compared with $89 \mathrm{~mm}, \mathrm{P}<0.001$ ) than women in the sham group (placebo) [22]. Conversely, a study by Miller et al. compared lidocaine and saline in paracervical blocks, found no difference in patients' perception of pain during and after surgical abortion among 52 women who participated in a double-blind randomized clinical trial, [34] the findings in this trial by Miller may have been limited by the small study size.

A similar study by Kan et al. demonstrated no difference in reported pain 
during dilation, aspiration, or following the procedure when comparing paracervical block with lidocaine to saline as placebo or to no injection in a randomized trial involving 135 women undergoing first trimester suction evacuation. This may be due to the fact that all women received cervical priming with misoprostol and received intravenous sedation [5] [35].

The trial by Gomez et al. may be limited by small study size [10], the waiting period between the administration/injection of anaesthetics and the starting of manual vacuum aspiration, [10] which is commonly less than 3 minutes in these studies may be responsible it is however, important to state that, in this study, the manual vacuum aspiration procedure was initiated 5 minutes after the block was administered.

The use of misoprostol to prime the cervix in those studies, is a factor which is usually associated with lower abdominal pain and could have aggravated the pains in addition, the studies described above were induced abortions in which the cervix is closed, it is necessary to dilate the cervix through mechanical procedures; this is the most painful part of the procedure [10] [19] unlike the focus of this present study (incomplete abortions), with open cervix and does not require dilation, also the technique of paracervical block injections of two sites and $10 \mathrm{mls}$ of lidocaine used in those studies is totally different from this study in which $20 \mathrm{mls}$ of lignocaine concentration was used and injected into four sites. The above explanation also probably explain that of the outcome of Gomez et al. which revealed no statistically significant differences between the pain reported by the patient nor in the degree of pain evaluated by the observer, even though a greater percentage of patients in group 2 (placebo group) was said to have experienced severe pain, both in the external observer's evaluation and in the patient's own evaluation and of course, it further explains, the Cochrane review performed in 2013 that identified no clear evidence of superiority or inferiority using paracervical blocks over other methods for pain control during procedures involving cervical dilation and uterine instrumentation [5]. But this review was not specifically directed toward the use of paracervical blocks during surgical abortions, let alone incomplete abortions, it therefore does not provide a strong basis to compare this finding with the target population of the current study.

There was a statistically significant higher postoperative overall satisfaction on Satisfaction visual Analogue score in women under the study group (paracervical block with lignocaine group), compares to the placebo group which is similar to the outcome of the study conducted by Renner et al. [22] where satisfaction scores, especially with pain control but also with the procedure, were significantly higher in paracervical block group.

Comparing of the Secondary outcomes in the two groups, revealed that a total of 29 women had additional analgesia; only 4 women in the study group and as many as 25 women required additional analgesia among the placebo group. Also, a statistically significant difference that was demonstrated while comparing the mean visual analogue scale of those that required additional analgesia in the two groups further confirm and suggest the efficacy of paracervical block with 
lignocaine over placebo during MVA of incomplete abortions and of note, is the remarkably higher mean VAS seen in the women that required additional analgesia among the placebo group.

There were no side effects or complication recorded in this study, which is similar to the work of Gomez et al. [10] that recorded no side effects or any related allergic reaction to paracervical block. Proper administration with appropriate dosage and avoiding inadvertent injection into the vessels can prevent many if not all of the most feared side effects.

The significant strength of this study include the fact it was a double blind randomized study, the use of external observer, who was also blind to the group assignment that was involved in the measurement of intraoperative pain, thorough training sessions organized for all the Doctors that were involved in the study, with a protocol detailing the objectives and the methodology to make them clear, and purposeful selection of a paracervical block technique that requires more needle sticks (four rather than two), more local anesthetic concentration $(20 \mathrm{~mL}$ rather than $10 \mathrm{~mL})$, and a longer waiting time of 5 minutes compared with less or no wait that were used in other studies.

\section{Study limitations}

Recruiting patients was a little difficult due to the social stigma associated with abortion and the public view of abortion (whether spontaneous or induced) as criminal.

Pain perception is subjective and may not be accurately measured and error of recall bias may not be rule out.

\section{Conclusion}

This study demonstrated that paracervical block with $1 \%$ lignocaine is more effective in reducing the pain perception during manual vacuum aspiration of incomplete abortions compared to placebo. It has added advantage of a higher overall satisfaction rate, shorter hospital stay, reduced need for additional analgesia and no side effect was reported.

\section{Acknowledgements}

We are using this opportunity to acknowledge the valuable contributions of Prof. Adesegun Fatusi of the Department of Community Health, Obafemi Awolowo University Teaching Hospitals Complex, Ile Ife, Osun State. We also appreciate Dr. Olorunfemi Ogundele of the Community Medicine Department, University of Medical Sciences, Ondo State, Nigeria, for his support in this article's writing.

\section{Conflicts of Interest}

The authors declare no conflicts of interest regarding the publication of this paper. 


\section{References}

[1] Akpanekpo, E., Umoessien, E. and Frank, E. (2017) Unsafe Abortion and Maternal Mortality in Nigeria: A Review. Pan-African Journal of Medicine, 1, 1-6.

[2] Oumer, M. and Manaye, A. (2019) Prevalence and Associated Factors of Induced Abortion among Women of Reproductive Age Group in Gondar Town, Northwest Ethiopia. Science Journal of Public Health, 7, 66.

https://doi.org/10.11648/j.sjph.20190703.11

[3] Hussein, F.M., Elmi, F.A., Mus, N.A. and Mumin, A. (2017) Factors Influencing Miscarriage among Pregnant Women in Banadir Hospital at Wadajir District. Jamhuriya University, Muqdisho, 23.

[4] Begum, R. and Begum, F. (2018) Recurrent Pregnancy Loss. Patient Management in Obstetrics \& Gynecology. 303.

[5] Joseph, K.S., Lee, L., Arbour, L., Auger, N., Darling, E.K., Evans, J., Little, J., McDonald, S.D., Moore, A., Murphy, P.A. and Ray, J.G. (2021) Stillbirth in Canada: Anachronistic Definition and Registration Processes Impede Public Health Surveillance and Clinical Care. Canadian Journal of Public Health, 112, 766-772.

[6] Tanvisut, R., Wanapirak, C., Piyamongkol, W., Sirichotiyakul, S., Tongprasert, F., Srisupundit, K., Luewan, S., Traisrisilp, K., Jatavan, P. and Tongsong, T. (2020) Cordocentesis-Associated Fetal Loss and Risk Factors: Single-Center Experience with 6650 Cases. Ultrasound in Obstetrics \& Gynecology, 56, 664-671.

[7] Lu, L., Li, J., Zhou, Y., Ma, H. and Hu, M. (2021) Complementary and Alternative Medicine for Threatened Miscarriage: Advantages and Risks. Evidence-Based Complementary and Alternative Medicine, 2021, Article ID: 5589116. https://doi.org/10.1155/2021/5589116

[8] Paul, R.C. (2019) Population-Based Estimates of Hepatitis E Virus Associated Mortality in Bangladesh.

[9] Maltzer, D., Maltzer, M.C., Wiebe, E.R., Halvorson-Boyd, G. and Boyd, C. (1999) Pain management. A Clinician's Guide to Medical and Surgical Abortion. In: Paul, M., Lichtenberg, E., Borgatta, L., Grimes, D. and Stubblefield, P., Eds., A Clinician's Guide to Medical and Surgical Abortion, Churchill Livingstone, Philadelphia, 73-89.

[10] Gomez, P.I., Gaitan, H., Nova, C. and Paradas, A. (2004) Paracervical Block in Incomplete Abortion Using Manual Vacuum Aspiration: Randomised Clinical Trial. Obstetrics \& Gynecology, 103, 943-951.

https://doi.org/10.1097/01.AOG.0000123269.86525.c4

[11] Chien, L.W. and Au, H.K. (2017) Interventions for Failed Family Planning. In: Family Planning, IntechOpen, London, 169-180. https://doi.org/10.5772/intechopen.72239

[12] Vonaldo, T. and Aurélio, M. (2006) Comparative Study of Midazolam with Ketamine S(+) versus Midazolam with Uterine Paracervical Block for Manual Intrauterine Aspiration. Revista Brasileira de Anestesiologia, 56, 443-453. https://doi.org/10.1590/S0034-70942006000500002

[13] Sun, Y.T. and Wu, J.S. (2018) The Visual Analogue Scale for Rating, Ranking and Paired-Comparison (VAS-RRP): A New Technique for Psychological Measurement. Behavior Research Methods, 50, 1694-1715. https://doi.org/10.3758/s13428-018-1041-8

[14] Rodríguez-Ruíz, A.F., MoralesÁlvarez, J.J. and Díaz-González, S.B. (2021) Advantages of Paracervical Block and Endouterine Manual Aspiration for the Treatment of Abnormal Uterine Bleeding Due to Endometrial Hypertrophy and Incomplete 
Abortion in the First Quarter. Ginecología y Obstetricia de México, 89, 279-285.

[15] Patel, A.J. and Thakkar, D.A. (2019) Para Cervical Block for Cervical Dilatation and Uterine Evacuation by MVA Method: A Safe and Effective Alternative at Tertiary Care, Teaching Hospital.

[16] Virkud, A. (2018) Practical Obstetrics and Gyneacology. First Trimester Termination Methods. 5th Edition.

[17] Dutta, D.C. (2015) Hemorrhage in Early Pregnancy. In: Dutta, D.C., Ed., Textbook of Obstetrics, 8th Edition, New Central Book Agency, 670.

[18] Wiebe, E. (1992) Comparison of the Efficacy of Different Local Anesthetics and Techniques of Local Anesthesia in Therapeutic Abortions. American Journal of $O b$ stetrics and Gynecology, 167, 131-134. https://doi.org/10.1016/S0002-9378(11)91645-7

[19] Glantz, J. and Shomento, S. (2001) Comparison of Paracervical Blocks Techniques during First Trimester Pregnancy Termination. International Journal of Gynecology \& Obstetrics, 72, 171-178. https://doi.org/10.1016/S0020-7292(00)00292-7

[20] Azman, A., Sakri, N.A., Kusni, N.A., Mansor, N.H. and Zakaria, Z.A. (2019) Manual Vacuum Aspiration: A Safe and Effective Surgical Management of Early Pregnancy Loss. International Journal of Reproduction, Contraception, Obstetrics and Gynecology, 8, 2257. https://doi.org/10.18203/2320-1770.ijrcog20192413

[21] Jekel, J.F., Katz, D.L., Elmore, J.G. and Wild, D. (2007) Epidemiology, Biostatistics and Preventive Medicine. Elsevier Health Sciences, Amsterdam, 201.

[22] Renner, R., Nichols, M., Jensen, J., Li, H. and Edelman, A. (2012) Paracervical Block for Pain Control in First-Trimester Surgical Abortion. A Randomized Controlled Trial. Obstetrics \& Gynecology, 119, 1030-1037. https://doi.org/10.1097/AOG.0b013e318250b13e

[23] Olusanya, O., Okpere, E. and Ezimokhai, M. (1985) The Importance of Social Class in Voluntary Fertility Control in a Developing Country. West African Journal of Medicine, 4, 205-212.

[24] Wiebe, E. and Rawling, M. (1995) Pain Control in Abortion. International Journal of Gynecology \& Obstetrics, 50, 41-46.

https://doi.org/10.1016/0020-7292(95)02416-A

[25] Donati, S., Medda, E., Proietti, S., Rizzo, L., Spinelli, A., Subrizi, D., et al. (1996) Reducing Pain of First Trimester Abortion under Local Anesthesia. European Journal of Obstetrics \& Gynecology and Reproductive Biology, 70, 145-149. https://doi.org/10.1016/S0301-2115(95)02583-9

[26] Phair, N., Jensen, J. and Nichols, M. (2002) Paracervical Block and Elective Abortion: The Effect on Pain of Waiting between Injection and Procedure. American Journal of Obstetrics and Gynecology, 186, 1304-1307. https://doi.org/10.1067/mob.2002.123734

[27] Pam, I. and Otubu, J. (2006) Miscarriages. In: Agboola, A., Ed., Textbook of Obstetrics and Gynaecology for Medical Students, 2nd Edition, Heinemann Educational Books, Ibadan, 103-126.

[28] Okonofua, F., Onwudiegwu, U. and Odunsi, O. (1992) Illegal Induced Abortion: A Study of 74 Cases in Ile-Ife, Nigeria. Tropical Doctor, 22, 75-78. https://doi.org/10.1177/004947559202200209

[29] Jubril, U., Olubiyi, S., Umar, A., Umar, A., Abubakar, I., Ibraheem, M., et al. (2014) Spontaneous Abortion among Women Admitted into the Gynaecological Wards of Three Selected Hospitals in Maiduguri, Nigeria. International Journal of Nursing 
and Midwifery, 6, 24-31. https://doi.org/10.5897/IJNM2013.0105

[30] Eduwem, D., Uduma, F., Okere, P., Abasiattai, A. and Ezirim, E. (2016) Obstetric Sonography in First Trimester Vaginal Bleeding (A Single Institution Study). Merit Research Journal of Medicine and Medical Sciences, 4, 356-362.

[31] Ijur, P. (2008) Reliability of the Visual Analog Scale for Measurement of Acute Pain. Academic Emergency Medicine, 8, 1153-1157. https://doi.org/10.1111/j.1553-2712.2001.tb01132.x

[32] Myles, P. (1999) The Pain Visual Analog Scale: Is It Linear or Nonlinear? Anesthesia \& Analgesia, 89, 1517. https://doi.org/10.1097/00000539-199912000-00038

[33] Egziabher, T., Ruminjo, J. and Sekadde-kigondu, C. (2002) Pain Relief Using Paracervical Block in Patients Undergoing Manual Vacuum Aspiration of Uterus. East African Medical Journal, 79, 530-534. https://doi.org/10.4314/eamj.v79i10.8815

[34] Miller, L., Jensen, M. and Stenchever, M. (1996) A Double-Blind Randomized Comparison of Lidocaine and Saline for Cervical Anesthesia. Obstetrics \& Gynecology, 87, 600-604. https://doi.org/10.1016/0029-7844(95)00463-7

[35] Kan, A., Ng, E. and Ho, P. (2004) The Role and Comparison of Two Techniques of Paracervical Block for Pain Relief during Suction Evacuation for First-Trimester Pregnancy Termination. Contraception, 70, 159-163.

https://doi.org/10.1016/j.contraception.2004.03.013 